Check for updates

Cite this: RSC Adv., 2018, 8, 21613

Received 19th April 2018

Accepted 3rd June 2018

DOI: $10.1039 / c 8 r a 03374 a$

rsc.li/rsc-advances

\title{
Controlled self-assembly into diverse stimuli- responsive microstructures: from microspheres to branched cylindrical micelles and vesicles $\uparrow$
}

\author{
Xiaoteng Zhou, Lingxiao Li, He Qin, Bo Ning, Junpei Li and Chengyou Kan (DD* \\ A series of amphiphilic PDMAEMA-SS-PCL chains with variable ratios of hydrophilic poly(2- \\ (dimethylamino)ethyl methacrylate) (PDMAEMA) to hydrophobic poly(e-caprolactone) (PCL) were \\ prepared via ring-opening polymerization, in which the two different moieties were linked via a disulfide \\ bond with reduction responsiveness. After cross-linking by the photodegradable o-nitrobenzyl linkage, \\ the amphiphilic chains could self-assemble into microspheres, branched cylindrical micelles and vesicles, \\ which were responsive to the reduction agent DL-dithiothreitol and UV light irradiation through different \\ mechanisms.
}

\section{Introduction}

Recently, fabrication of microscale stimuli-responsive polymeric systems has increasingly become a hot research field in material, pharmaceutics, catalysis, etc. ${ }^{1}$ Various stimuliresponsive microstructures including microspheres, micro/ nano-gels, micelles and especially vesicles, which are similar to organism structure, have shown a powerful methodology for applications in drug delivery, microreactors and biosensors. ${ }^{1-6}$ In the applications of these polymeric microstructures, stimuliresponsiveness is a necessary function which can make them recognize their microenvironment and react in a dynamic way, mimicking the responsiveness of living organisms. ${ }^{7}$ Besides traditional thermo- and $\mathrm{pH}$-sensitive systems, reductionsensitive architectures based on disulfide bonds, which are commonly found in organisms and can react with intra-cellular glutathione, have drawn more attention especially in drug delivery systems. ${ }^{8}$ Moreover, because light-responsive systems can be rapidly induced at a specific time and are affected less than other experimental variables, light-triggered polymeric systems are also attractive now to achieve diverse functions in response to illumination of a specific wavelength. Up to now, most investigations of light responsive systems have been focused on simple micelles and microstructures such as vesicles and branched micelles have not been reported widely. ${ }^{9}$

Among the above applications, encapsulation of therapeutic agents into polymer microstructures has been successfully used in the development of new drug carriers. A number of design

Department of Chemical Engineering, Key Laboratory of Advanced Materials of Ministry of Education, Tsinghua University, Beijing 100084, People's Republic of China.E-mail: kancy@mail.tsinghua.edu.cn

$\dagger$ Electronic supplementary information (ESI) available. See DOI: 10.1039/c8ra03374a parameters which affect the functional behaviour of carriers, including the choice of polymer, particle size and surface chemistry, have been adjusted to optimize their performance in vivo. ${ }^{10}$ In recent years, some investigations have confirmed that the shape of the microstructures can significantly impact the performance of polymer drug carriers, and have indicated that different morphologies of micro/nano structures exhibit different solubilization capacities, blood circulation times, biodistribution, toxicity, cellular uptake and intracellular fate. ${ }^{11,12}$ Thus, more and more attention has been paid to control morphology in common drug delivery for anti-cancer applications. ${ }^{13-16}$ Most multiple stimuli-responsive drug delivery systems can only be self-assembled into a spherical shape, ${ }^{17-19}$ and how to make these systems into different controlled morphologies is indeed meaningful for real application. It has been demonstrated that amphiphilic block copolymers in solution could be self-assembled into highly organized microstructures of different morphologies such as spheres, rods, lamellas and vesicles because of their architecture with two disparate physical property blocks. ${ }^{20-22}$ Since the morphologies of these microstructures used to be accurately tuned by the design of relative hydrophobic/hydrophilic block lengths, block arrangement, solvent composition and so on, ${ }^{20}$ controlled self-assembly through these pathways can help to adjust an appropriate microstructure to meet our demands.

Herein, we demonstrate a novel amphiphilic polymeric system to obtain three microstructures of different morphologies including microspheres, branched cylindrical micelles and vesicles, which just originate from the similar chains with diverse hydrophobic/hydrophilic ratios. With the help of the disulfide bond between the disparate segments and the photodegradable cross-linker incorporated into the amphiphilic chain, the microstructures all have reduction- and lightresponsive properties. In addition, it is well known that the 
hydrophilic PDMAEMA segment is responsive to $\mathrm{pH}$ and temperature, ${ }^{23,24}$ and the hydrophobic PCL segment is recognized by its enzymatic degradation property. ${ }^{25,26}$ Thus, these microstructures can be used in many applications with diverse requirements and the different structures may also provide various physical performances and loading capacities to disparate cargos. ${ }^{27}$

\section{Experimental}

\section{Materials}

5-Hydroxy-2-nitrobenzaldehyde (Adams, 98\%), sodium tetrahydroborate $\left(\mathrm{NaBH}_{4}, 98 \%\right.$, Tianjin Yongda Chemical Reagent Co. Ltd), bromoacetyl bromide (TCI, 98\%), 4-dimethylaminopyridine (DMAP, Adams, 99\%), e-caprolactone (CL, Adams, 99\%), and stannous octoate $\left(\mathrm{Sn}(\mathrm{Oct})_{2}\right.$, Admas, 95\%) were of analytical grade. PDMAEMA-SS-OH $\left(M_{\mathrm{w}}=20708 \mathrm{~g} \mathrm{~mol}^{-1}\right.$, PDI = 1.127) was synthesized through an ATRP method as described previously. ${ }^{28}$ DL-Dithiothreitol (DTT, Aladdin, 99\%), tetrahydrofuran (THF), triethylamine (TEA), toluene, and dichloromethane were of analytical grade and purchased from Beijing Chemical Works (Beijing, China).

\section{Synthesis of the light-stimulation responsive cross-linker $\mathrm{Br}$ - ONB-Br}

Firstly, 5-hydroxy-2-nitrobenzyl alcohol was synthesized by a reduction reaction as follows. To a $50 \mathrm{~mL}$ flask 5-hydroxy-2nitrobenzaldehyde $(0.5000 \mathrm{~g}, 3 \mathrm{mmol})$ and $20 \mathrm{~mL}$ of methanol were added and stirred. A methanol solution of $\mathrm{NaBH}_{4}$ $(0.2300 \mathrm{~g}, 6 \mathrm{mmol}$ in $20 \mathrm{~mL}$ methanol) was added dropwise into the flask at $0{ }^{\circ} \mathrm{C}$ in an ice bath. The reaction mixture was stirred for $4 \mathrm{~h}$ at $25{ }^{\circ} \mathrm{C}$, and then poured into $\mathrm{H}_{2} \mathrm{O}(30 \mathrm{~mL})$. After adjusting the $\mathrm{pH}$ to around 6 using $0.1 \mathrm{M} \mathrm{HCl}$, the solution was extracted with diethyl ether three times, dried by $\mathrm{MgSO}_{4}$ overnight, filtered, and concentrated using a rotary evaporator to obtain the target compound ( $0.4346 \mathrm{~g}, 2.57 \mathrm{mmol}$, yield $85.7 \%$ ). ${ }^{1} \mathrm{H}$ NMR (DMSO-D6, $\delta$, ppm, see Fig. S1†): 10.86 (s, 1H), 8.04, 7.21 and $6.76(\mathrm{~m}, 3 \mathrm{H}), 5.5(\mathrm{~s}, 1 \mathrm{H}), 4.77(\mathrm{~s}, 2 \mathrm{H}){ }^{29}$

Then, 5-hydroxy-2-nitrobenzyl alcohol (0.5070 g, $3 \mathrm{mmol})$, TEA (2.3 mL, $16 \mathrm{mmol}$ ) and DMAP (49.00 mg, $0.4 \mathrm{mmol})$ were dissolved in dry dichloromethane $(30 \mathrm{~mL})$ in a $50 \mathrm{~mL}$ flask under a $\mathrm{N}_{2}$ atmosphere, and the flask was immersed in an ice bath for $30 \mathrm{~min}$. A solution of bromoacetyl bromide $(1.05 \mathrm{~mL}, 12 \mathrm{mmol})$ in dichloromethane $(10 \mathrm{~mL})$ was then added dropwise into the flask over $15 \mathrm{~min}$. After stirring at $25{ }^{\circ} \mathrm{C}$ for $22 \mathrm{~h}$, the white solid was removed by filtration, and the reaction mixture was transferred to a separatory funnel and diluted with $10 \mathrm{~mL}$ of dichloromethane. After this, the mixture was washed sequentially with $1 \mathrm{M} \mathrm{HCl}(10$ $\mathrm{mL})$, a saturated solution of $\mathrm{NaHCO}_{3}(10 \mathrm{~mL})$ and water $(10 \mathrm{~mL})$, and the resulting organic phase was then dried with anhydrous magnesium sulfate overnight. The mixture was concentrated under reduced pressure via a rotary evaporator, and the resulting crude product was purified by column chromatography with mixtures of $3: 1$ hexane/ethyl acetate (by volume). After being dried in a vacuum at $50{ }^{\circ} \mathrm{C}$ for $24 \mathrm{~h}$, the pure photodegradable cross-linker Br-ONB-Br was obtained (0.8335 g, 2.03 mmol, yield
67.7\%). ${ }^{1} \mathrm{H}$ NMR $\left(\mathrm{CDCl}_{3}, \delta, \mathrm{ppm}\right.$, see Fig. S2 $\left.\dagger\right): 8.25$ (d, $\left.1 \mathrm{H}\right), 7.46$ $(\mathrm{s}, 1 \mathrm{H}), 7.32(\mathrm{~d}, 1 \mathrm{H}), 5.61(\mathrm{~s}, 2 \mathrm{H}), 4.07(\mathrm{~s}, 2 \mathrm{H}), 3.95(\mathrm{~s}, 2 \mathrm{H}) .{ }^{28}$

\section{Synthesis of linear PDMAEMA-SS-PCL amphiphilic copolymers with diverse hydrophobic ratios by ROP polymerization}

PDMAEMA-SS-OH (0.5000 g, $0.028 \mathrm{mmol}), \mathrm{CL}(0.3420 \mathrm{~g}$, $3 \mathrm{mmol}$ for sample AC1, $0.500 \mathrm{~g}, 4.38 \mathrm{mmol}$ for sample AC2, $1.069 \mathrm{~g}, 9.375 \mathrm{mmol}$ for sample AC3), $\mathrm{Sn}(\mathrm{Oct})_{2}(25.02 \mathrm{mg}, 6.13 \times$ $\left.10^{-2} \mathrm{mmol}\right)$, and toluene $(8 \mathrm{~mL})$ were charged into a $25 \mathrm{~mL}$ flask equipped with a magnetic stirrer. The flask was placed into an oil bath and the reaction was carried out at $95{ }^{\circ} \mathrm{C}$ for $24 \mathrm{~h}$. The reaction mixture was poured into cold diethyl ether, and the precipitate was collected and dried under vacuum at $50{ }^{\circ} \mathrm{C}$ for $48 \mathrm{~h}$ to obtain the product.

\section{Self-assembly of the linear amphiphilic polymer chain}

PDMAEMA-SS-PCL block copolymer (10 mg) was first dissolved in $50 \mathrm{~mL}$ of $\mathrm{THF}$, and $10 \mathrm{~mL}$ of trimethylamine was then added dropwise to the solution. Then, the solution was concentrated via evaporation at room temperature to about $5 \mathrm{~mL}$. After dialysis (molecule weight cutoff $3500 \mathrm{Da}$ ) of the solution with water, an aqueous dispersion $\left(0.33 \mathrm{mg} \mathrm{mL}^{-1}\right)$ of the selfassembled microstructures was obtained.

\section{Self-assembly of the cross-linked amphiphilic polymer chain} with $\mathrm{Br}-\mathrm{ONB}-\mathrm{Br}$

A typical procedure for the self-assembly of the cross-linked amphiphilic polymer chain with $\mathrm{Br}-\mathrm{ONB}-\mathrm{Br}$ is described as follows. PDMAEMA-SS-PCL block copolymer $(10 \mathrm{mg})$ was first dissolved in $30 \mathrm{~mL}$ of THF, and a solution of $\mathrm{Br}-\mathrm{ONB}-\mathrm{Br}(10 \mu \mathrm{L})$ dissolved in $20 \mathrm{~mL}$ of THF was added dropwise into the polymer solution. After one-day reaction at $70{ }^{\circ} \mathrm{C}, 10 \mathrm{~mL}$ of TEA was added to the reaction system and the solution was concentrated via evaporation at room temperature to about $5 \mathrm{~mL}$. After dialysis (molecular weight cutoff, $3500 \mathrm{Da}$ ) of the solution with water, the aqueous dispersion $\left(0.33 \mathrm{mg} \mathrm{mL}^{-1}\right)$ of the selfassembly cross-linked microstructures was obtained.

\section{Reduction stimuli-responsiveness of the microstructures self- assembled from the cross-linked PDMAEMA-SS-PCL}

The DTT solution (20 mM) was first prepared by dissolving $31 \mathrm{mg}$ of DTT in $10 \mathrm{~mL}$ of PBS buffer solution $(\mathrm{pH}=7.4)$, and the dispersion of the self-assembled PDMAEMA-SS-PCL microstructures $\left(0.33 \mathrm{mg} \mathrm{mL}{ }^{-1}\right)$ was then added into the solutions. After being stirred at $25{ }^{\circ} \mathrm{C}$ for different periods of time, the resulting microstructures were characterized by TEM and DLS analysis.

Light stimuli-responsiveness of the microstructures selfassembled from the cross-linked PDMAEMA-SS-PCL

$3 \mathrm{~mL}$ of the solution $\left(0.33 \mathrm{mg} \mathrm{mL}^{-1}\right)$ of the self-assembled PDMAEMA-SS-PCL microstructures was exposed to a UV-led point light source (IWATA UV-101D, $365 \mathrm{~nm}, 36 \mathrm{~mW} \mathrm{~cm} \mathrm{~cm}^{-2}$ ) for $0.5 \mathrm{~h}$, and the resulting microstructures were characterized by TEM. 


\section{Characterization}

${ }^{1} \mathrm{H}$ NMR spectra of the samples were recorded using a JEOL ECS-400 spectrometer with $\mathrm{CDCl}_{3}$ as the solvent, especially DMSO-D6 for the 5-hydroxy-2-nitrobenzyl alcohol. FTIR spectra were recorded on a Nicolet 560 fourier transform infrared analyzer in the range from 4000 to $400 \mathrm{~cm}^{-1}$ with a resolution of $4 \mathrm{~cm}^{-1}$. The average molecular weight was measured by gel permeation chromatography (GPC) (SHIMADZU LC-20A) using THF as eluent. The morphologies of the different structures were characterized on a HITACHI H-7650 transmission electron microscope (TEM), and the samples for TEM observation were prepared by spraying the dispersion $\left(5 \mu \mathrm{L}, 0.33 \mathrm{mg} \mathrm{mL}^{-1}\right)$ onto 300-mesh copper grids and drying at room temperature. The hydrodynamic diameter, size distribution and zeta potential were determined on a Malvern Zetasizer Nano ZS90.

\section{Results and discussion}

Design and characteristics of the amphiphilic PDMAEMA-SSPCL chains with different hydrophobic/hydrophilic ratios

It is well known that poly( $\varepsilon$-caprolactone) (PCL) has great biodegradability and biocompatibility in the pharmaceutical field. ${ }^{30-33}$ Because the PCL segments can encapsulate hydrophobic anti-cancer drugs by hydrophobic interactions and its chain length can affect the morphology and stability of the copolymers which can be self-aggregated into particles or fibres used as a drug carrier, PCL has shown great potential in drug delivery in vivo when it makes up the hydrophobic part of the polymer chain..$^{30,31}$ On the other hand, because of its $\mathrm{pH}$ - and thermo-sensitivity, hydrophilicity and ease of quaternisation, poly(2-(dimethylamino)ethyl methacrylate) (PDMAEMA) has been utilized widely in drug delivery systems. ${ }^{23,24,34}$ For example, using the electrostatic interactions between its cationic groups and DNA or siRNA, PDMAEMA segments can stably package the gene, preventing that encapsulated from extracellular digestion and extending the opportunity for efficient delivery into target cells by endocytosis. ${ }^{11,34,35}$ The co-polymer PHA-PDMAEMA formed from the combination of PDMAEMA with polyhydroxyalkanoates (PHAs), which are a class of diverse biodegradable polyesters, has been synthesized. ${ }^{36}$ Researchers have found that this copolymer could co-deliver hydrophobic anticancer drugs by hydrophobic interactions and genes by electrostatic attraction and had a great result when entering liver cancer cells. ${ }^{37,38}$ Thus, in our work, amphiphilic PDMAEMA-SSPCL block copolymers, in which the hydrophilic DMAEMA segment and hydrophobic CL segment were linked by $-\mathrm{S}-\mathrm{S}-$, were designed to synthesize stimuli-responsive microstructures with different morphologies. The copolymers were then crosslinked by $\mathrm{Br}-\mathrm{ONB}-\mathrm{Br}$ to obtain a light-stimuli-responsive property. The synthetic routes of the linear and cross-linked PDMAEMA-SS-PCL block copolymers as well as the photodegradable cross-linker Br-ONB-Br are shown in Scheme 1.

Designing the relative hydrophobic/hydrophilic block lengths to obtain diverse morphologies of the block copolymer has been used to obtain "Crew-Cut" aggregates with multiple morphologies via tuning of the hydrophilic part of polystyrene-

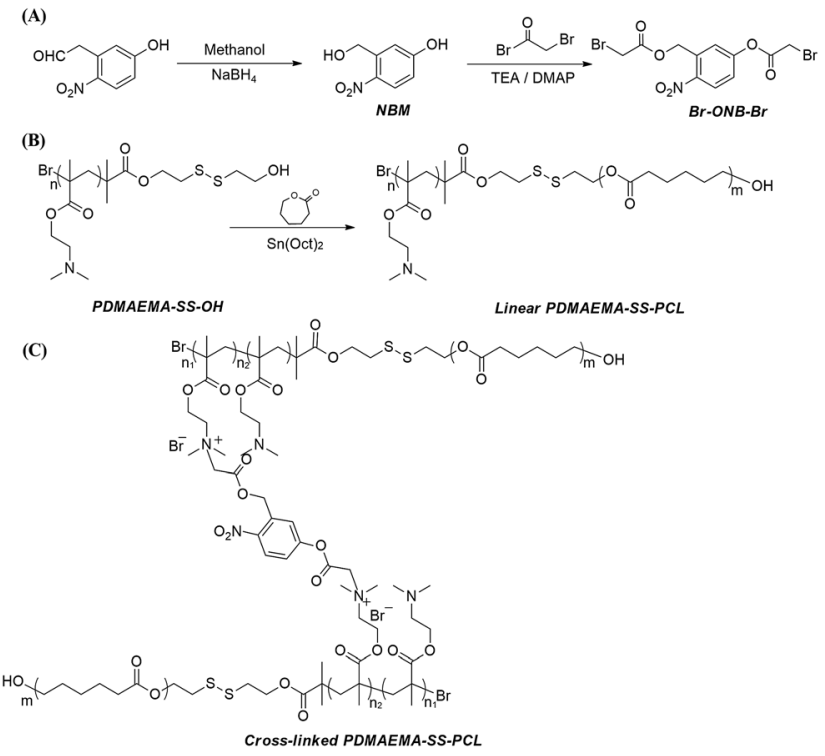

Scheme 1 The synthetic routes of (A) photodegradable cross-linker $\mathrm{Br}-\mathrm{ONB}-\mathrm{Br}$, (B) amphiphilic linear PDMAEMA-SS-PCL, and (C) crosslinked PDMAEMA-SS-PCL with $\mathrm{Br}-\mathrm{ONB}-\mathrm{Br}$.

block-polyacrylic acid (PSt- $b$-PAA), ${ }^{39}$ and this method shows potential for forming diverse architectures of copolymer by means of hydrophobic interactions. In addition, this type of self-assembly into micelles, vesicles and so on has an apparent resemblance to cells, because hydrophilic regions can form in a hydrophobic matrix which is surrounded by a hydrophilic surface. So according to Scheme 1(B), three types of the linear block copolymers $\mathrm{PDMAEMA}_{n}-\mathrm{SS}-\mathrm{PCL}_{m}$ with diverse hydrophobic/hydrophilic ratios were prepared through ringopening polymerization (ROP) between PDMAEMA-SS-OH and $\varepsilon$-caprolactone, and their chemical structure and

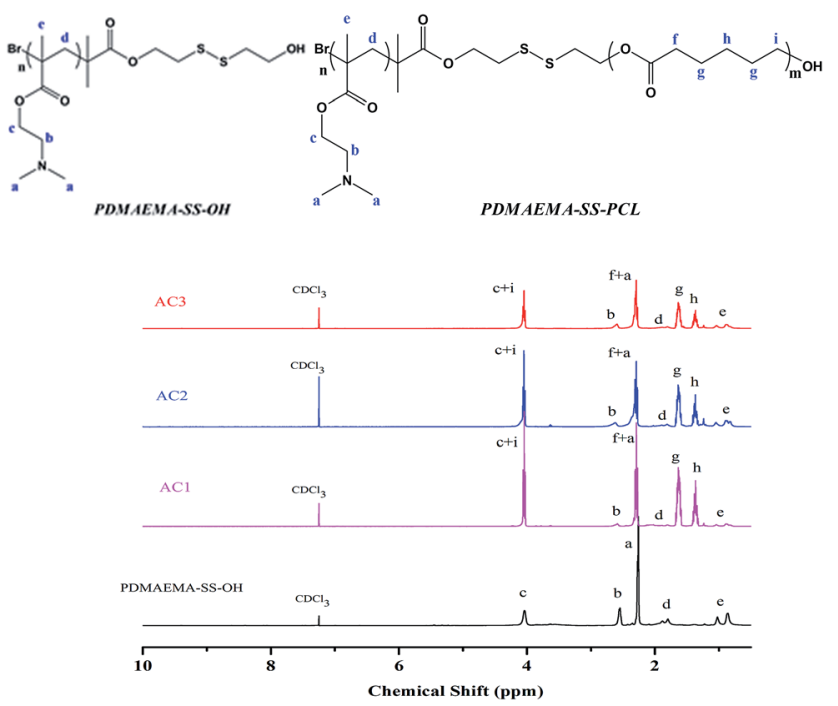

Fig. $1{ }^{1} \mathrm{H}$ NMR spectra of PDMAEMA ${ }_{n}-\mathrm{SS}-\mathrm{PCL}_{m}$ with diverse hydrophobic ratios for $A C 1, A C 2$ and $A C 3$ compared with that of the initial PDMAEMA-SS-OH. 
Table 1 Comparisons between different types of linear and cross-linked PDMAEMA-SS-PCL with diverse hydrophobic/hydrophilic ratios

\begin{tabular}{lllllllll}
\hline Sample & $m: n^{a}$ & Br-ONB-Br ${ }^{b}$ & $M_{\mathrm{w}}{ }^{c}$ & $D_{\mathrm{h}}{ }^{d}(\mathrm{~nm})$ & $D_{\mathrm{T}}{ }^{e}(\mu \mathrm{m})$ & Zeta $(\mathrm{mV})$ & $\left.\mathrm{CAC}_{(\mathrm{mg} \mathrm{mL}}{ }^{-1}\right)$ & Morphology \\
\hline AC1 & $555: 132$ & None & 88123 & 403.7 & 0.336 & 53.9 & 0.182 & Micelle \\
AC2 & $264: 132$ & None & 51994 & 389.3 & 0.386 & 25.5 & 0.191 & Micelle \\
AC3 & $158: 132$ & None & 36637 & 387.2 & 0.395 & 55.3 & 0.209 & Hollow micelle \\
x-AC1 & $555: 132$ & Yes & - & - & 1.50 & 17.5 & 0.093 & Microsphere \\
x-AC2 & $264: 132$ & Yes & - & - & $3.04-4.08$ & 9.3 & 0.091 & Branched micelle \\
x-AC3 & $158: 132$ & Yes & - & - & $3.22-7.26$ & 16.0 & 0.079 & Vesicle
\end{tabular}

${ }^{a} m: n$ is the hydrophobic/hydrophilic segments ratio calculated based on ${ }^{1} \mathrm{H}$ NMR and GPC. ${ }^{b}$ Photodegradable cross-linker. ${ }^{c}$ Measured by GPC. ${ }^{d}$ Measured by the DLS method as shown in Fig. S3. ${ }^{e}$ Obtained from TEM images shown in Fig. S5.

composition were confirmed by ${ }^{1} \mathrm{H}$ NMR (see Fig. 1). Characteristic peaks of the PCL segments in the block copolymers were easily recognized, which presented at $\mathrm{g}, \mathrm{h}, \mathrm{f}$ and $\mathrm{i}$. Moreover, on the basis of the integration of the $(\mathrm{c}+\mathrm{i})$ peak and $(\mathrm{f}+\mathrm{a})$ peak, the specific value of $(3 m+n):(m+n)$ was first obtained for each sample, and on the basis of the $M_{\mathrm{w}}$ of the initial PDMAEMA-SS$\mathrm{OH}$, then the relative value $m: n$ of the hydrophobic/hydrophilic block lengths in the amphiphilic molecules was estimated, which agreed with the value of $M_{\mathrm{w}}$ measured by GPC (see Table 1).

Because its ester bond can be easily cleaved by UV light irradiation, $o$-nitrobenzyl ester has been used as a photosensitive protective group for carboxylic acids in organic synthesis ${ }^{\mathbf{4 0}}$ and used to prepare photoresist materials. ${ }^{41}$ Recently, more attention has been paid to these kinds of photosensitive compounds in the fields of photoresists for nanolithography, ${ }^{42}$ photo-stimuli-responsive materials for controlled release ${ }^{\mathbf{4 3 , 4 4}}$ and stimuli-regulated "traceless" crosslinking. ${ }^{45}$ In our previous work, a novel photodegradable cross-linker $\mathrm{Br}-\mathrm{ONB}-\mathrm{Br}$ based on $o$-nitrobenzyl ester was synthesized, and we found that it had an excellent stimuli-responsiveness to UV light irradiation in the releasing experiment. ${ }^{25}$ In this work, the cross-linker $\mathrm{Br}$ ONB-Br was synthesized with a higher yield using an improved method as shown in Scheme 1(A), and the ${ }^{1} \mathrm{H}$ NMR spectra of the precursor 5-hydroxy-2-nitrobenzyl alcohol and $\mathrm{Br}-\mathrm{ONB}-\mathrm{Br}$ are given in Fig. S1 and $\mathrm{S} 2 . \dagger$ The linear PDMAEMA-SS-PCL was cross-linked by $\mathrm{Br}-\mathrm{ONB}-\mathrm{Br}$ in THF via a quaternisation reaction between the bromine and tertiary amine groups of the DMAEMA unit. After $24 \mathrm{~h}$ of reaction, the solution was placed in a dialysis bag to perform the self-assembly through changing the medium from THF to $\mathrm{H}_{2} \mathrm{O}$ and purifying by removing unreacted $\mathrm{Br}-\mathrm{ONB}-\mathrm{Br}$ simultaneously. ${ }^{27,42}$ As shown in Fig. 2, the peaks belonging to $\mathrm{Br}-\mathrm{ONB}-\mathrm{Br}$ appeared on the FTIR spectra of the cross-linked polymers, indicating that the photodegradable cross-linker actually makes up a new segment between a couple of PDMAEMA-SS-PCL chains.

\section{Comparison of the microstructures self-assembled from linear and cross-linked PDMAEMA-SS-PCL chains}

In order to confirm the influence of the cross-linking, the selfassemblies of the linear PDMAEMA-SS-PCL (sample AC1, AC2 and AC3) were carried out under the same conditions as the cross-linked ones, and their colloidal property and morphology were then characterized. DLS analysis (see Table 1 and Fig. S3†) indicated that the diameter of the micelles self-assembled from the linear PDMAEMA-SS-PCL was about $400 \mathrm{~nm}$, which agreed with the TEM images (see Scheme 2: AC1, AC2, AC3).

The amphiphilic chains of AC3 might be self-assembled on the surface of THF droplets like in the process of styrene emulsification as reported before, ${ }^{46}$ in which a similar copolymer PCL-SS-PDMAEMA with a ratio of hydrophobic/hydrophilic lengths similar to the value of AC3 was synthesized and used as surfactant to prepare PS nanoparticles, so when the THF core was removed by the dialysis in water, the hollow micelles appeared (Scheme 2: AC3). As Table 1 and Fig. S4† indicate, the linear sample shows a higher zeta potential than the corresponding cross-linked one, and it may have been caused by the quarternisation reaction in the cross-linking step, in which the number of positive charges on the surface of the self-assembled microstructures decreased.

The self-assemblies of the cross-linked PDMAEMA-SS-PCL copolymers were very different from those of the linear ones, and specific microstructures (see Scheme 2: x-AC1, x-AC2, xAC3) with morphologies such as microspheres, branched cylindrical micelles and vesicles were generated. The crosslinked PDMAEMA-SS-PCL chains could be restricted in one dimension because of the covalent interaction between the PDMAEMA-SS-PCL chain and Br-ONB-Br, so their

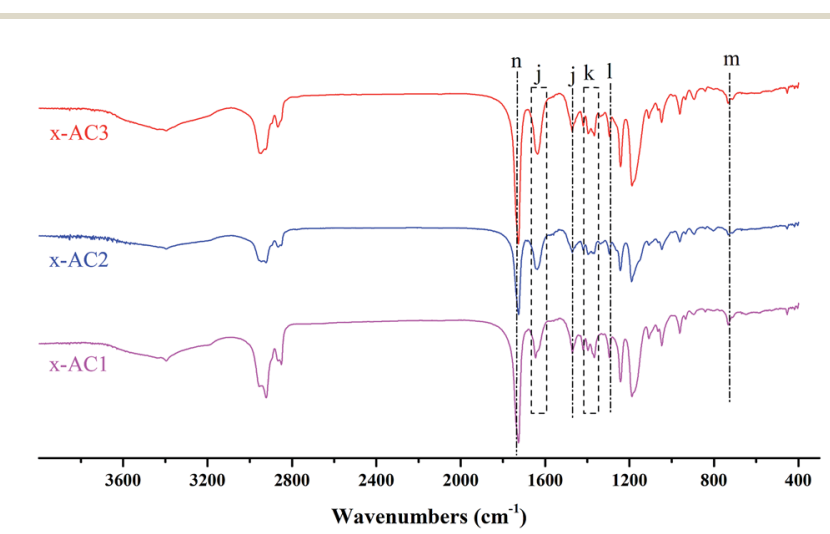

Fig. 2 FTIR spectra of the cross-linked PDMAEMA $A_{n}-S S-P C L_{m}$. (j) $1645 \mathrm{~cm}^{-1}, 1471 \mathrm{~cm}^{-1}\left(\mathrm{C}=\mathrm{C}\right.$ stretching of benzene), (k) $1367 \mathrm{~cm}^{-1}$ $\left(\mathrm{N}=\mathrm{O}\right.$ stretching of $\left.-\mathrm{NO}_{2}\right),(\mathrm{l}) 1296 \mathrm{~cm}^{-1}(\mathrm{C}-\mathrm{N}$ stretching) (m) $733 \mathrm{~cm}^{-1}(\mathrm{C}-\mathrm{H}$ bending of ortho-substituted benzene) and (n) $1725 \mathrm{~cm}^{-1}$ ( $\mathrm{C}=\mathrm{O}$ stretching). 


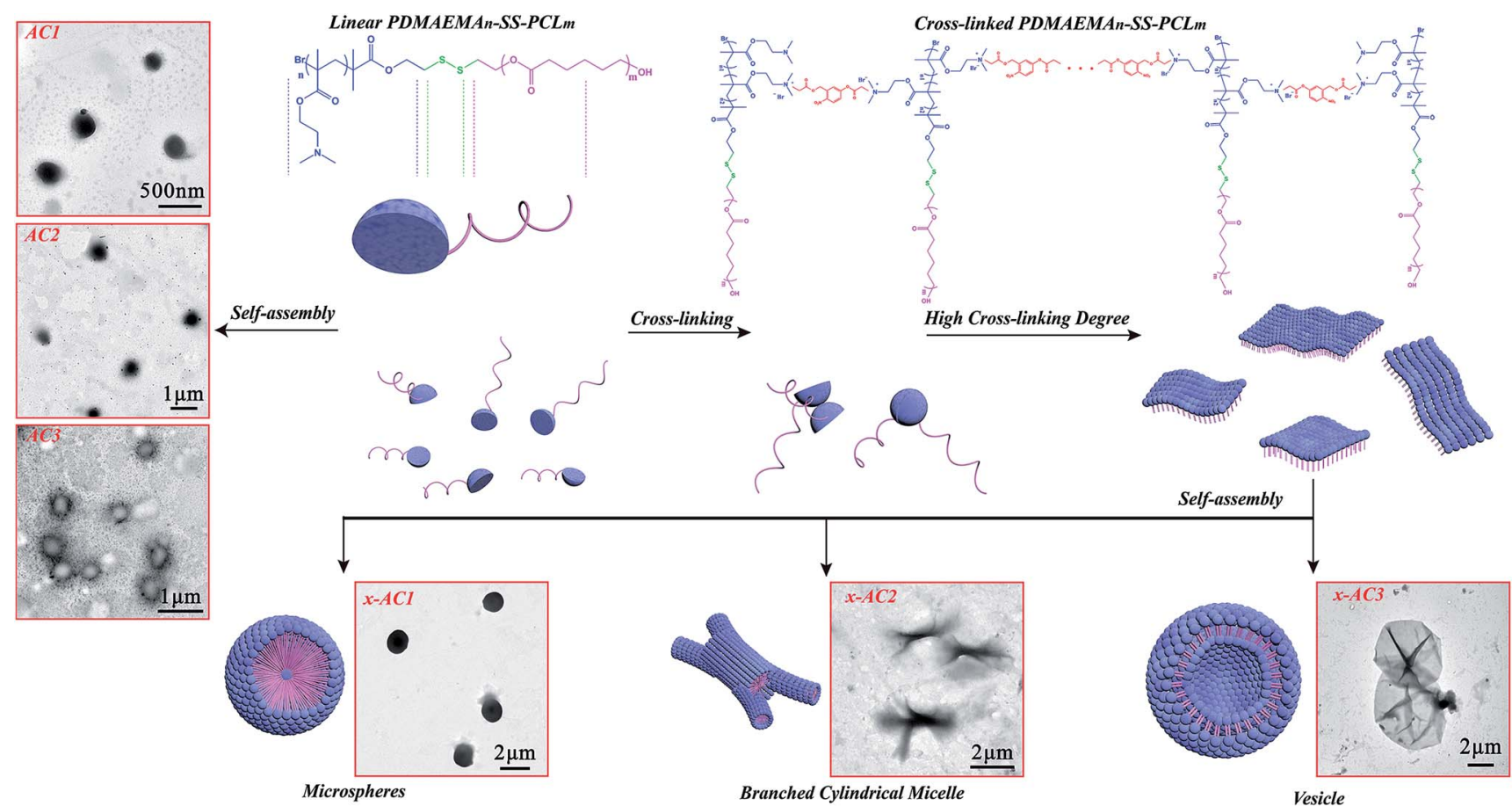

Scheme 2 Self-assembly process of the cross-linked PDMAEMA-SS-PCL chains with different hydrophobic/hydrophilic ratios.

aggregations depended not only on the hydrophobic interaction, but also on the covalent bond among every amphiphilic chain. It is clear that the diameters of the self-assembled microstructures from the cross-linked copolymers were greater than those from the linear ones. As indicated in Fig. $\mathrm{S} 5, \dagger$ the microspheres were about $1.5 \mu \mathrm{m}$ in diameter, and the branched cylindrical micelles were $3-4 \mu \mathrm{m}$ in one dimension but only $250-400 \mathrm{~nm}$ in the middle areas. The vesicles were not very homogeneous, and the diameters ranged from about 3.5 $\mu \mathrm{m}$ to $7.2 \mu \mathrm{m}$, which might result from the different crosslinking levels. In order to understand the formation mechanism of different microstructures, the critical aggregate concentration (CAC) was measured by the conductivity titration method $^{47}$ (see Table 1 and Fig. S6 $\dagger$ ). Because of the crosslinking, the molecular weight and the original particle volume of PDMAEMA-SS-PCL increased, which certainly enhanced the probability of aggregation. ${ }^{48,49}$ The CAC values of the crosslinked PDMAEMA-SS-PCL solutions were obviously lower than that of the corresponding linear ones, and since the concentrations of the PDMAEMA-SS-PCL solutions were all beyond their CAC values, there is no doubt that the selfassembled copolymer chains existed in the system.

Based on the above results, the formation mechanisms of the different self-assembed microstructures are proposed. As shown in Scheme 2, the PDMAEMA segments of the PDMAEMA-SS-PCL chains could be covalently linked by $\mathrm{Br}-$ ONB-Br in THF which is a good solvent for both blocks, and ultimately formed into single layers like two-dimensional materials when the cross-linking reached a certain degree. The change of dissolving medium might drive them into threedimensional shapes, ${ }^{\mathbf{5}}$ like the solvent-responsive bilayer microstructures, the self-folding of which could be triggered by solvent after certain cross-linking as reported before. ${ }^{51,52}$ So, the sample x-AC1 with the longest hydrophobic chain could be selfassembled from single layers into a microsphere with one or numerous hydrophilic cores, like the reported large compound micelles in which the hydrophilic segments formed the corona of micelles and the core consisted of numerous reverse micelles with hydrophilic islands in continuous hydrophobic phase. ${ }^{53-55}$ In this study, the existence of hydrophilic cores was proved by encapsulating hydrophilic Rhodamine B (RhB) into the microspheres (see Fig. S7 $\dagger$ ). As for the branched cylindrical micelle originating from $\mathrm{x}-\mathrm{AC} 2$, its formation process is similar to that of a reported poly(ferrocenyldimethylsilane)- $b$-poly(2vinylpyridine) system. ${ }^{56}$ After the cross-linking, these single layers were not homogeneous, and the layers with a high degree of cross-linking formed a thicker core in the middle. Subsequent growth of multiple thinner cores by the other layers occurred to form a branched cylindrical architecture. Like the system of the similar amphiphilic polylactide-block-poly( $N$-isopropyl acrylamide) (PLA- $b$-PNIPAAm) shell-cross-linked by hexanediol diacrylate, ${ }^{57}$ the sample $\mathrm{x}-\mathrm{AC} 3$ in which the hydrophilic shell was cross-linked by $\mathrm{Br}-\mathrm{ONB}-\mathrm{Br}$ could also aggregate into vesicles by hydrophobic interactions. Since different crosslinking levels led to different swelling behaviour in aqueous media, ${ }^{57}$ x-AC3 showed disparate morphology compared with uncross-linked AC3. Because of the cross-linking process, the self-assembled units of $\mathrm{x}$-AC3 were much bigger than those of the uncross-linked system (AC3), resulting in the formation of larger vesicles than common ones. ${ }^{58}$ Moreover, by comparing $\mathrm{x}-$ AC3 with $\mathrm{x}$-AC1, the sample $\mathrm{x}-\mathrm{AC} 3$ was shown to have more tertiary amine groups for cross-linking, which made the initial 
amphiphilic layer much larger before the self-assembly process, and as a result, the vesicles were much larger than the microspheres self-assembled from x-AC1.

This phenomenon of the changes between the diverse morphologies is consistent with the packing parameter, $P=v$ / $(a l)$, which was introduced by Israelachvili ${ }^{59}$ and utilized to predict the resulting morphologies, where (for an amphiphilic $\mathrm{AB}$ diblock co-polymer) $v$ is the volume of the hydrophobic block, $l$ is the chain length normal to the interface, and $a$ ( $a=$ $3 v / R, R$ is the packing radius) is the interfacial area between two blocks. ${ }^{59,60}$ It is generally believed that for the self-assembly of amphiphilic diblock copolymer, the copolymers with $P<1 / 3$ will form spherical micelles, and those with $1 / 3<P<1 / 2$ will favor the formation of cylindrical micelles, whereas when $1 / 2<P<1$, enclosed membrane structures (vesicles, also known as polymersomes) will be preferred..$^{\mathbf{5 9 6 1 - 6 3}}$ In this study, as the length of PCL segment decreased, the values of $l$ and $v$ both decreased, but according to $a=3 v / R$, with an increase in $R$ caused by the cross-linking process, $a$ is reduced more drastically than $v$. Thus, the value of $P$ increased with the length of the PCL segment decreasing and as results, the sample x-AC1 with the longest PCL segments self-assembled into a spherical shape, the sample $\mathrm{x}-\mathrm{AC} 2$ with PCL segments of medium length preferred to form a branched architecture, and the sample $\mathrm{x}$ AC3 with the shortest PCL segments self-aggregated into a vesicle structure. ${ }^{51,64}$

\section{Reduction- and light-responsive properties of the microstructures self-assembled from cross-linked PDMAEMA-SS-PCL chains}

As mentioned above, the disulfide bond and the photodegradable linkage in the amphiphilic PDMAEMA-SS-PCL copolymers could endow the self-assembled architectures with reductionand light-responsive properties. To verify the reductionresponsive property, DL-dithiothreitol (DTT), a disulfide bond reducing agent, was used to treat the three microstructures at the same concentration for different lengths of time.

As Fig. $3\left(a_{1}-a_{3}\right)$ indicates, the microspheres seemed to be destroyed in comparison with those of the untreated sample (see Scheme 2: $x$-AC1). Area I and II in Fig. 3( $\left.a_{1}\right)$ were in an incomplete reduction process because of a limited treatment time of 2 days. Area I shows the initial stage that DTT molecules started to penetrate into the microstructure, and area II with the central core was closer to the final state in which the central core still existed but the edge was destroyed into small irregular fragments like area III (magnified in Fig. 3( $\left.a_{2}\right)$ ). When the treatment time was prolonged to 5 days, all of the microspheres were completely broken into small pieces (see Fig. $3\left(\mathrm{a}_{3}\right)$ ) as in area III. For the branched cylindrical microstructure, the destruction first occurred in the two terminal parts of the branched micelle (Fig. $3\left(b_{1}\right)$ ), and the amplification of area IV is given in Fig. $3\left(b_{2}\right)$. After 5 days treatment, most of the architectures were broken into pieces (Fig. $3\left(b_{3}\right)$ ), and only a few architectures were incompletely destroyed, leaving a small central part of the structures (see Fig. S8 $\dagger$ ). Furthermore, from the TEM images and DLS analysis (see Fig. S9†), we can see that
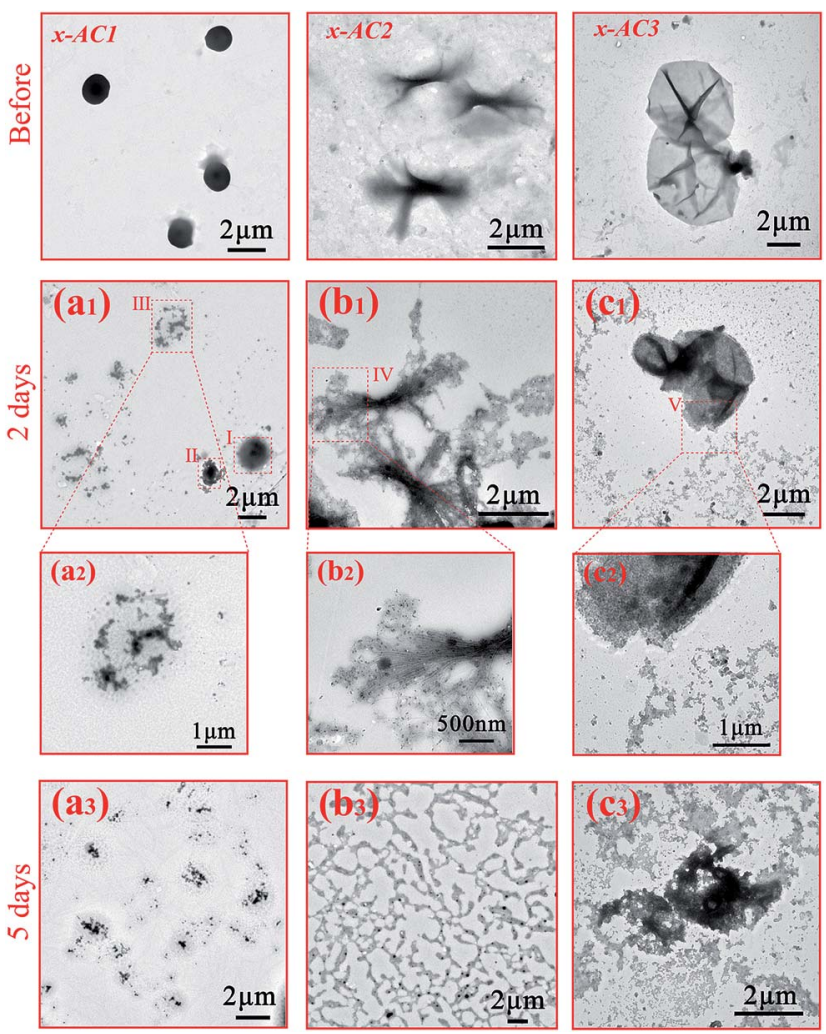

Fig. 3 TEM images of the cross-linked PDMAEMA-SS-PCL treated with DTT for different lengths of time: $\left(a_{1}\right)$ and $\left(a_{2}\right) x-A C 1,2 d,\left(a_{3}\right) x-$ $A C 1,5 d ;\left(b_{1}\right)$ and $\left(b_{2}\right) x-A C 2,2 d,\left(b_{3}\right) x-A C 2,5 d ;\left(c_{1}\right)$ and $\left(c_{2}\right) x-A C 3,2 d$, $\left(c_{3}\right) x-A C 3,5 d$

the destruction occurred more violently for the branched micelles. After 5 days reduction, the size of the branched micelles decreased sharply to $200 \mathrm{~nm}$, while the size of the microspheres only decreased from about $1.5 \mu \mathrm{m}$ to $488 \mathrm{~nm}$. This significant difference mainly came from the distinction of the intensity of the hydrophobic interactions based on the length of the hydrophobic chain, and another incentive was that the scale of the branched micelle microstructures was only about 250-400 $\mathrm{nm}$ in one dimension (see Fig. S5†), which was significantly less than the diameter of microspheres and made the branched micelles break down more thoroughly. The destruction of the vesicles was similar to that of the branched micelles. During the reduction process, small pieces were gradually separated from the microstructures (see Fig. 3( $\left.c_{1}\right)$ ) and the enlarged image of area $\mathrm{V}$ is shown in Fig. 3( $\left.c_{2}\right)$, but the framework still existed in this process. When the treatment time increased to 5 days, most of the pieces became dissociative fragments away from the framework (see Fig. $3\left(c_{3}\right)$ ), and the size of the degradative vesicles was around 600-1000 nm with a wide size distribution (see Fig. S9†), which is much smaller than the original.

The light responsive property of the cross-linked architectures was evaluated by UV light irradiation for $0.5 \mathrm{~h}$, and the results are given in Fig. 4(a)-(c). It is obvious that the UV stimulation didn't cause dramatic destruction like the reduction stimulation, and some fragments appeared on the edges of the microspheres and on the tail of the branched micelles in 

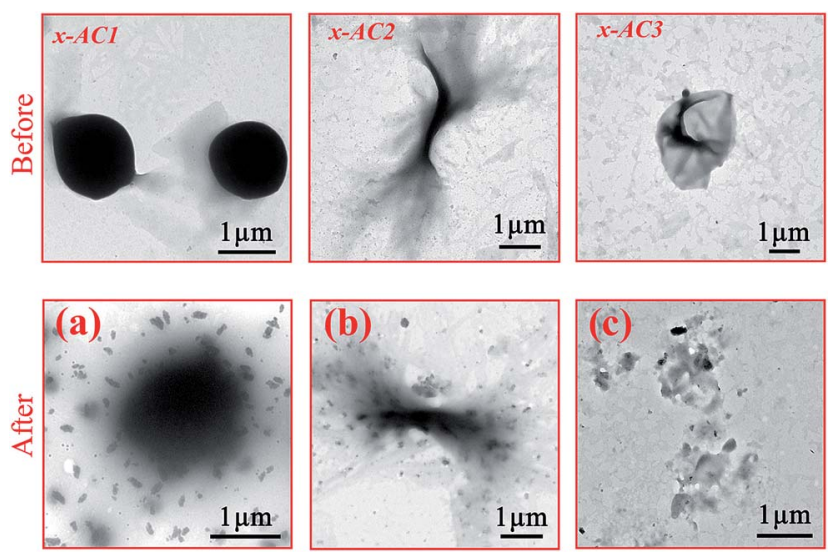

Fig. 4 TEM images of the cross-linked PDMAEMA-SS-PCL before and after UV light irradiation: (a) X-AC1 (b) X-AC2 (c) $\mathrm{x}-\mathrm{AC} 3$.
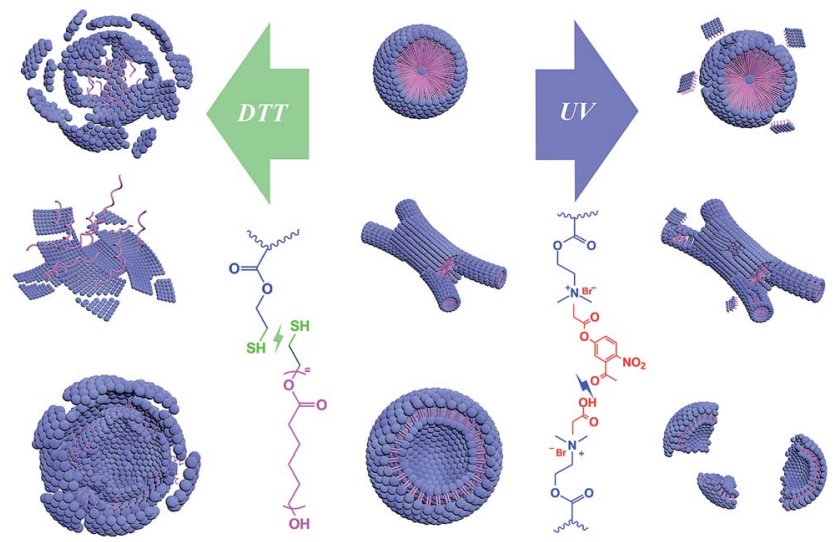

ving

Scheme 3 Schematic diagram for the destruction of three microstructures by reduction- and light-stimulations.

one dimension after the irradiation (see Fig. 4(a), (b) and S10(a), (b) †). It was noted that the vesicles were broken into a number of lamellas (see Fig. 4(c) and S10(c)†), indicating that they were much easier to be destroyed by the UV light than other two architectures because of the different hydrophilic block lengths.

So as shown in Scheme 3, the reduction stimulation might destroy the -S-S- linkage between the hydrophobic and hydrophilic segments, and as a result, the hydrophilic chain is broken from the microstructures and dispersed or even dissolved in the aqueous phase. ${ }^{65}$ However, the UV light irradiation just cleaves an ester bond of the cross-linking structures, like scissors "cut" out some parts of the linking "wires" on the surface. ${ }^{66}$ Based on the different results between the two responsivenesses, this might provide a new system to release drugs in diverse intensities or a selective releasing system for disparate drugs.

\section{Conclusions}

In summary, we have designed and demonstrated a novel simple amphiphilic cross-linked PDMAEMA-SS-PCL system to controllably obtain three different microstructures including microspheres, branched cylindrical micelles and vesicles. The three types of microstructures were obtained just by varying the hydrophobic/hydrophilic ratios and cross-linking, and the results show that they were all responsive to reductant and UV light stimulation via two different mechanisms. This may provide a fresh idea for preparing smart systems which will be responsive to different stimulations and the three different morphologies may help us to pick out the best performance shape in specific applied scenarios. Combining the $\mathrm{pH}$ and temperature responsiveness of the PDMAEMA moiety and the enzymatic degradation property of the PCL moiety, this smart polymeric system can even have quintuple stimuli-responsive properties which we will continue to use for drug delivery and release in our follow-up research and we believe this system will meet a lot of requirements for its various morphologies and stimuli-responsiveness.

\section{Conflicts of interest}

There are no conflicts to declare.

\section{Acknowledgements}

This work was supported by grants from the National Key Research and Development Program of China (2017YFD0200704) and the Young Elite Scientists Sponsorship Program by CAST (2017QNRC001).

\section{Notes and references}

1 M. A. Stuart, T. S. Huck, J. Genzer, M. Müller, C. Ober, M. Stamm, G. B. Sukhorukov, I. Szleifer, V. T. Tsukruk, M. Urban, F. Winnik, S. Zauscher and I. Luzinov, Nat. Mater., 2010, 9, 101-113.

2 D. E. Discher and A. Eisenberg, Science, 2002, 297, 967-973.

3 Y. Zhu, B. Yang, S. Chen and J. Du, Prog. Polym. Sci., 2017, 64, 1-22.

4 N. Rapoport, Prog. Polym. Sci., 2007, 32, 962-990.

5 S. Ahn, R. M. Kasi, S. C. Kim, N. Sharma and Y. Zhou, Soft Matter, 2008, 4, 1151-1157.

6 J. M. Anderson and M. S. Shive, Adv. Drug Delivery Rev., 2012, 64, 72-82.

7 S. Mura, J. Nicolas and P. Couvreur, Nat. Mater., 2013, 12, 991-1003.

8 B. Deng, P. Ma and Y. Xie, Nanoscale, 2015, 7, 12773-12795.

9 M. H. Li and P. Keller, Soft Matter, 2009, 5, 927-937.

10 J. A. Champion, Y. K. Katare and S. Mitragotri, J. Controlled Release, 2007, 121, 3-9.

11 N. P. Truong, W. Gu, I. Prasadam, Z. Jia, R. Crawford, Y. Xiao and M. J. Monteiro, Nat. Commun., 2013, 4, 1902.

12 M. Elsabahy and K. L. Wooley, Chem. Soc. Rev., 2012, 41, 2545-2561.

13 A. Kakkar, G. Traverso, O. C. Farokhzad, R. Weissleder and R. Langer, Nat. Rev. Chem., 2017, 1, 0063. 
14 Y. Li, J. Lin, Y. Huang, Y. Li, X. Yang, H. Wu, S. Wu, L. Xie, L. Dai and Z. Hou, ACS Appl. Mater. Interfaces, 2015, 7, 25553-25559.

15 S. Qin, A. Zhang, S. Cheng, L. Rong and X. Zhang, Biomaterials, 2017, 112, 234-247.

16 B. Karagoz, L. Esser, H. T. Duong, J. S. Basuki, C. Boyer and T. P. Davis, Polym. Chem., 2014, 5, 350-355.

17 T. Ramasamy, H. B. Ruttalaa, B. Guptaa, B. K. Poudela, H. Choic, C. S. Yonga and J. O. Kima, J. Controlled Release, 2017, 258, 226-253.

18 X. Li, C. Liu, S. Wang, J. Jiao, D. Di, T. Jiang, Q. Zhao and S. Wang, Mater. Sci. Eng., C, 2017, 71, 594-603.

19 X. Wu, Y. J. Tan, H. T. Toh, L. H. Nguyen, S. H. i. Kho, S. Y. Chew, H. S. Yoon and X. Liu, Chem. Sci., 2017, 8, 3980-3988.

20 Y. Mai and A. Eisenberg, Chem. Soc. Rev., 2012, 41, 59695985.

21 K. Kita-Tokarczyk, J. Grumelard, T. Haefele and W. Meier, Polymer, 2005, 46, 3540-3563.

22 H. Cui, Z. Chen, S. Zhong, K. L. Wooley and D. J. Pochan, Science, 2007, 317, 647-650.

23 Y. Xie, F. Yu, W. Tang, B. O. Alade, Z. Peng, Y. Wang, J. Li and D. Oupický, Macromol. Biosci., 2017, 1700194.

24 A. J. Convertine, C. Diab, M. Prieve, A. Paschal, A. S. Hoffman, P. H. Johnson and P. S. Stayton, Biomacromolecules, 2010, 11, 2904-2911.

25 E. Murray, B. C. Thompson, S. Sayyar and G. Wallace, Polym. Degrad. Stab., 2015, 111, 71-77.

26 M. A. Woodruff and D. W. Hutmacher, Prog. Polym. Sci., 2010, 35, 1217-1256.

27 S. Venkataraman, J. L. Hedrick, Z. Y. Ong, C. Yanga, P. L. Rachel, P. T. Hammond and Y. Yang, Adv. Drug Delivery Rev., 2011, 63, 1228-1246.

28 Z. Q. Cao, X. T. Zhou and G. J. Wang, ACS Appl. Mater. Interfaces, 2016, 8, 28888-28896.

29 J. Yin, H. Hu, Y. Wu and S. Liu, Polym. Chem., 2011, 2, 363371.

30 C. Zheng, H. Gao, D. Yang, M. Liu, H. Cheng, Y. Wu and X. J. Loh, Mater. Sci. Eng., C, 2017, 74, 110-116.

31 P. Charoongchit, J. Suksiriworapong, K. Sripha, S. Mao, A. Sapin-Minet, P. Maincent and V. B. Junyaprasert, Mater. Sci. Eng., C, 2017, 72, 444-455.

32 A. O. Basar, S. Castro, S. Torres-Giner, J. M. Lagaron and H. T. Sasmazel, Mater. Sci. Eng., C, 2017, 81, 459-468.

33 M. Basko, M. Bednarek, L. Vlaminck, P. Kubisaa and F. E. Du Prez, Eur. Polym. J., 2017, 89, 230-240.

34 X. Fan, S. Jiang, Z. Li and X. J. Loh, Mater. Sci. Eng., C, 2017, 73, 275-284.

35 Y. Xiang, N. N. Linn Oo, J. P. Lee, Z. Li and X. J. Loh, Drug Discovery Today, 2017, 22, 1318-1335.

36 Z. Li and X. J. Loh, Wiley Interdiscip. Rev.: Comput. Mol. Sci., 2016, 9, e1429.

37 X. Wang, S. S. Liow, Q. Wu, C. Li, C. Owh, Z. Li, X. J. Loh and Y. Wu, Macromol. Biosci., 2017, 17, 1700186.
38 H. Cheng, Z. Wu, C. Wu, X. Wang, S. S. Liow, Z. Li and Y. Wu, Mater. Sci. Eng., C, 2018, 83, 210-217.

39 L. Zhang and A. Eisenberg, Science, 1995, 268, 1728-1731.

40 B. Amit, U. Zehavi and A. Patchornik, Isr. J. Chem., 1974, 12, 103-113.

41 H. Barzynski and D. Sänger, Macromol. Mater. Eng., 1981, 93, 131-141.

42 L. Chen, Y. K. Goh, H. Cheng, B. W. Smith, P. Xie, W. Montgomery, A. K. Whittaker and I. Blakey, J. Polym. Sci., Part A: Polym. Chem., 2012, 50, 4255-4265.

43 J. Jiang, X. Tong, D. Morris and Y. Zhao, Macromolecules, 2006, 39, 4633-4640.

44 Z. Cao, H. Wu, J. Dong and G. Wang, Macromolecules, 2014, 47, 8777-8783.

45 X. Wang, G. Liu, J. Hu, G. Zhang and S. Liu, Angew. Chem., Int. Ed., 2014, 126, 3202-3206.

46 Y. Zhang and H. Zhao, Polymer, 2015, 64, 277-284.

47 C. Wang, S. Yin, S. Chen, H. Xu, Z. Wang and X. Zhang, Angew. Chem., Int. Ed., 2008, 120, 9189-9192.

48 M. J. Tizzotti, M. C. Sweedman, C. Schäfer and R. G. Gilbert, Food Hydrocolloids, 2013, 31, 365-374.

49 N. Jain, S. Trabelsi, S. Guillot, D. McLoughlin, D. Langevin, P. Letellier and M. Turmine, Langmuir, 2004, 20, 8496-8503.

50 C. Ye and V. V. Tsukruk, Science, 2015, 347, 130-131.

51 M. H. Stenzel, X. Fan, J. Y. Chung, Y. X. Lim, Z. Li and X. J. Loh, ACS Appl. Mater. Interfaces, 2016, 8, 33351-33370.

52 J. Guan, H. He, D. J. Hansford and L. J. Lee, J. Phys. Chem. B, 2005, 109, 23134-23137.

53 C. Feng, G. Lu, Y. Li and X. Huang, Langmuir, 2013, 29, 10922-10931.

54 B. Xu, G. Gu, C. Feng, X. Jiang, J. Hu, G. Lu, S. Zhang and X. Huang, Polym. Chem., 2016, 7, 613-624.

55 W. Jiang, Y. Zhou and D. Yan, Chem. Soc. Rev., 2015, 44, 3874-3889.

56 H. Qiu, V. A. Du, M. A. Winnik and I. Manners, J. Am. Chem. Soc., 2013, 135, 17739-17742.

57 M. Hales, C. B. Kowollik and T. P. Davis, Langmuir, 2004, 20, 10809-10817.

58 J. Du and S. P. Armes, J. Am. Chem. Soc., 2005, 127, 1280012801.

59 J. N. Israelachvili, D. J. Mitchell and B. W. Ninham, J. Chem. Soc., Faraday Trans. 2, 1976, 72, 1525-1568.

60 A. Blanazs, S. P. Armes and A. J. Ryan, Macromol. Rapid Commun., 2009, 30, 267-277.

61 D. S. Choi, M. S. Jhon and H. Eyring, J. Chem. Phys., 1970, 53, 2608-2614.

62 C. Lu and M. W. Urban, Prog. Polym. Sci., 2017, 78, 24-46.

63 M. Antonietti and S. Förster, Adv. Mater., 2003, 15, 13231333.

64 N. J. Warren and S. P. Armes, J. Am. Chem. Soc., 2014, 136, 10174-10185.

65 M. H. Lee, J. L. Sessler and J. S. Kim, Acc. Chem. Res., 2015, 48, 2935-2946.

66 X. Hua, F. Chen, N. Li and W. Bai, Polym. Degrad. Stab., 2017, 142, 51-66. 